\title{
Antagonism of a learned taste aversion following repeated administrations of electroconvulsive shock
}

\author{
JOHN R. VOGEL \\ Central Nervous System Section, William H. Rorer, Inc. \\ Fort Washington, Pennsylvania 19034
}

\begin{abstract}
Injection of methyl atropine immediately following ingestion of sweetened condensed milk induced a marked aversion to the taste of milk. In a second experiment, the learned taste aversion was attenuated when repeated administrations of electroconvulsive shock were given 4 days after taste-aversion training. This effect was only temporary, and the taste aversion reappeared within 21 days after termination of electroconvulsive shocks (Experiment III). Similar attenuation of other punishments by repeated administrations of electroconvulsive shock has been reported. In this respect, learned taste aversions appear to resemble other effects of punishment.
\end{abstract}

Animals develop aversions to distinctive tastes which are followed by noxious consequences, particularly when ingestion of a novel food is followed by administration of certain drugs. A widely held interpretation of this phenomenon is that malaise produced by the drug becomes conditioned to food cues and inhibits subsequent consumption of that food (Revusky \& Garcia, 1970). Thus, taste aversions inhibit consummatory responding much as other punishments inhibit operant responding.

Treatments that antagonize other punishments should also antagonize learned taste aversions. One treatment which antagonizes punishment by footshock (Geller \& Seifter, 1960) is the benzodiazepine drug, chlordiazepoxide. Chlordiazepoxide has recently been shown to attenuate a learned taste aversion to saccharin (Cappell \& LeBlanc, 1973). Clody, Vogel, and Taub (1974) reported that chlordiazepoxide antagonized the acquisition as well as the performance of a learned taste aversion to sweetened condensed milk. These studies clearly demonstrate that chlordiazepoxide, a drug which attenuates other punishments, also antagonizes learned taste aversions.

Repeated administrations of electroconvulsive shock antagonize the effects of punishment. This has been demonstrated with conditioned emotional responses in the rat (Hunt \& Brady, 1951) and the monkey (Willi, 1969). In these experiments, a conditioned emotional response (responding suppressed by a neutral stimulus previously paired with unavoidable shock) was superimposed on a stable baseline behavior. After the conditioned emotional response became established, repeated administrations of electroconvulsive shock were given. The treatments antagonized the conditioned emotional response but did not disrupt baseline responding. This indicates that the reduction in the conditioned emotional response was due to an antagonism of the effects of punishment. The absence of a disruption in baseline responding suggested that repeated administrations of electroconvulsive shock did not simply lead to memory loss.

One might suspect that repeated administrations of electroconvulsive shock would antagonize the effects of other punishments such as learned taste aversions. The present series of experiments was designed to examine the effects of repeated electroconvulsive shocks on a learned aversion to sweetened condensed milk.

\section{EXPERIMENT I}

Anticholinergic drugs have been reported to induce learned taste aversions in the laboratory rat (Berger, 1972; Vogel \& Clody, 1972). Experiment I was conducted to determine a dose of the anticholinergic drug, methyl atropine, that would reliably induce an aversion to the taste of sweetened condensed milk.

\section{Method}

Subjects. Eighty adult male Holtzman albino rats were used. The Ss weighed approximately $165 \mathrm{~g}$ at the start of the experiment. Each group consisted of 10 rats.

Apparatus. The Ss were trained and tested in a $23.5 \times 20.5 \times$ $29.3 \mathrm{~cm}$ box with a clear acrylic plastic top and sides, having aluminum end walls. The box was fitted with a glass drinking tube that contained a $33 \%$ solution of sweetened condensed milk (Borden's Star brand) in room-temperature tap water. The tube extended through a $19-\mathrm{mm}$ opening in the end wall of the cubicle. Each $\mathrm{S}$ could easily lick the tube while standing on the grid floor. Individual licks were monitored by a drinkometer which was connected to programming equipment located in an adjacent room.

Procedure. The Ss were deprived of both food and water $24 \mathrm{~h}$ prior to training and test sessions. For training, each $\mathrm{S}$ was placed in the apparatus and allowed $10 \mathrm{~min}$ to complete 100 licks at the drinking tube. Upon completion of 100 licks, the S was removed from the box, injected with $0.06,0.13,0.25,0.50$, or $1.0 \mathrm{mg} / \mathrm{kg}$ methyl atropine and returned to its home cage with ad lib food and water. On the test session (4 days later), Ss (food and water deprived) were again placed in the apparatus and the time to complete 100 licks was recorded; Ss were allowed a maximum of $300 \mathrm{sec}$ to complete 100 licks at the tube. The experiment was run in two replications; groups receiving distilled 
water and $0.25 \mathrm{mg} / \mathrm{kg}$ methyl atropine were repeated in both phases of the experiment. Methyl atropine (atropine methyl nitrate) was prepared as a solution in sterile distilled water and was injected intraperitoneally at a volume of $1.0 \mathrm{ml} / \mathrm{kg}$. A control injection consisted of $1 \mathrm{ml} / \mathrm{kg}$ sterile distilled water which was also administered intraperitoneally.

\section{Results}

The results of Experiment $I$ are shown in Fig. 1. On the training day, three Ss (control, 0.13, and $0.25 \mathrm{mg} / \mathrm{kg}$ ) failed to complete 100 licks and were discarded from the experiment. The times to complete 100 licks on the test session were compared using the Mann-Whitney $U$ test (two-tailed). A comparison of the results obtained with the two control groups and the two groups given $0.25 \mathrm{mg} / \mathrm{kg}$ methyl atropine indicated that the replications did not differ, and for statistical purposes the data were combined. Ss given methyl atropine following training with milk failed to complete 100 licks on the test session or took longer to complete 100 licks than did controls given distilled water alone $(p<.01$ in each case), all of which completed 100 licks. These results indicated that doses ranging from 0.06 to $1.0 \mathrm{mg} / \mathrm{kg}$ methyl atropine induced marked aversions to the taste of sweetened condensed milk.

\section{EXPERIMENT II}

Experiment II was designed to examine the effects of repeated administrations of electroconvulsive shock on an established aversion to the taste of sweetened condensed milk. Four days after taste-aversion training, a series of 21 electroconvulsive shocks was begun.

\section{Method}

Subjects. Eighteen adult male Holtzman albino rats served as Ss and weighed approximately $170 \mathrm{~g}$ at the start of the experiment.

Apparatus. The apparatus consisted of a box described in Experiment I and an electroshock source set to deliver a 60-mA shock for a duration of $0.25 \mathrm{sec}$ through ear clips coated with electrode paste.

Procedure. All Ss were given training with milk and injected with methyl atropine as described in Experiment I. A dose of $0.25 \mathrm{mg} / \mathrm{kg}$ was chosen because it induced a marked taste aversion in Experiment I. The Ss were then randomly divided into three groups shown in Fig. 2: one group was tested after 21 sham treatments; a second group was tested before electroconvulsive shock treatments and tested a second time after 21 electroconvulsive shock treatments; a third group was tested only after 21 electroconvulsive shock treatments. Electroconvulsive shock or sham (electrodes attached but no current applied) treatments were administered at 9:00 a.m., 12 noon, and 3:00 p.m. on each of 7 consecutive days, beginning on the 4th day following training.

\section{Results}

The results of Experiment II are shown in Fig. 2. The mean time for all Ss to complete 100 licks on the training session (prior to administration of drug) is shown by the dotted line in Fig. 2. Ss that received methyl atropine after licking milk, and were tested after sham treatments, demonstrated a marked aversion to the

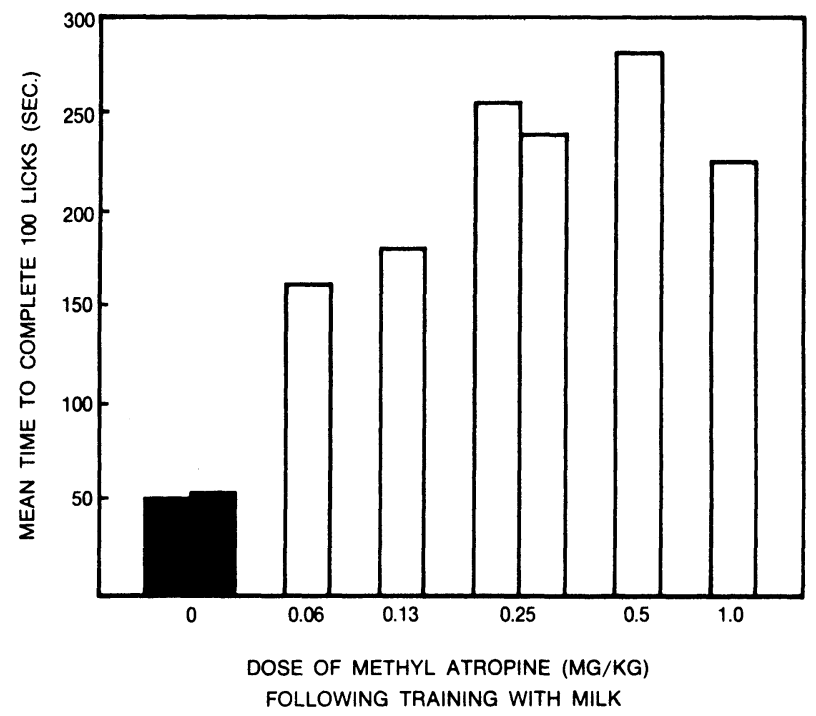

Fig. 1. Mean time to complete 100 licks of sweetened condensed milk on the test session. Ss were injected with various doses of methyl atropine immediately following training with milk and were tested one week later.

taste of sweetened condensed milk, i.e., they took significantly longer to complete 100 licks on the test session than they did on the training session $(U=0$, $\mathrm{p}<.002)$. A similar aversion was shown by Ss which also received the drug and were tested prior to electroconvulsive shock treatments. After these Ss were given 21 electroconvulsive shock treatments, a dramatic change in their reaction to sweetened condensed milk occurred. When they were retested after the treatments, they resumed drinking milk $(U=3, p<.002$, as

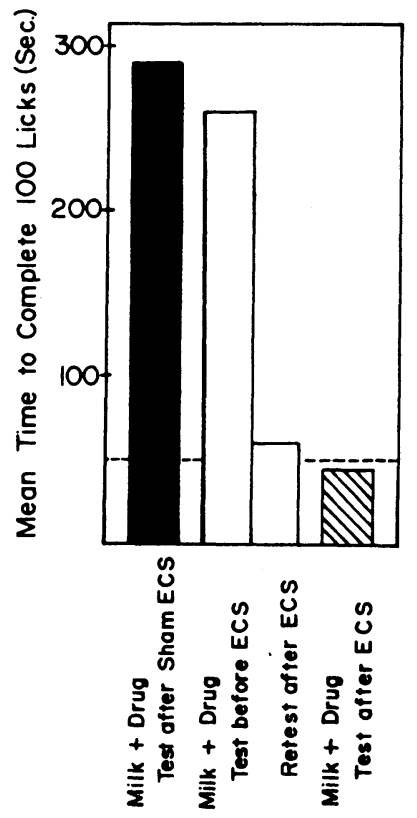

Fig. 2. Mean time to complete 100 licks of sweetened condensed milk on the test session. Ss were injected with methyl atropine immediately following training with milk and were tested after electroconvulsive shock (ECS) or sham treatments. 
compared with scores prior to electronconvulsive shock treatment) and showed no evidence of a taste aversion. The third group, which was not tested prior to receiving 21 electroconvulsive shock treatments, did not show the expected aversion to sweetened condensed milk and licked significantly faster than the group tested after sham treatments $(U=0, p<.01)$ or the group tested before electroconvulsive shock treatments $(U=1.5$, $\mathrm{p}<.02$ ). Thus, taste aversions resulting from the association of sweetened condensed milk with the drug methyl atropine were antagonized by repeated administrations of electroconvulsive shock.

\section{EXPERIMENT III}

Experiment III was designed to evaluate the persistence of the antagonism of a taste aversion by repeated administrations of electroconvulsive shock. The Ss were given repeated treatments after taste-aversion training and then tested at various intervals after the last electroconvulsive shock.

\section{Method}

Subjects. Thirty-three adult male Holtzman albino rats weighing approximately $180 \mathrm{~g}$ at the start of the experiment served as Ss. They were randomly assigned to ECS $(\mathrm{N}=18)$ or sham-ECS $(\mathrm{N}=15)$ groups.

Apparatus. The apparatus was the same as that described in Experiments I and II.

Procedure. Because Experiment III provided for a long treatment-test interval ( 21 days), it was assumed that a higher dose of methyl atropine would insure a stable taste aversion over the long treatment-test interval. Therefore, all Ss were given training with milk and injected with 0.5 instead of $0.25 \mathrm{mg} / \mathrm{kg}$ methyl atropine. They were then divided into two groups and, beginning 4 days after training, they were given either 21 electroconvulsive shock treatments or 21 sham treatments over a period of 7 days (3/day). Following the completion of these treatments, each of the groups was further subdivided such that Ss were tested with milk at intervals of 1,7 , or 14 days following the last electroconvulsive shock or sham treatment $(N=6$ for each ECS/time period, $\mathrm{N}=5$ for each sham-ECS/time period).

\section{Results}

The results of Experiment III are illustrated in Fig. 3. One animal (Group ECS-1) died during the course of electroconvulsive shock treatments. The times to complete 100 licks on the test session did not differ for the various sham groups; therefore, for statistical comparisons, the scores for these groups were combined. Ss in Group ECS-1 were tested 1 day following the last electroconvulsive shock treatment; these rats completed 100 licks on the test session significantly faster than did sham-treated Ss $(U=7, p<.02)$. This result replicates the finding in Experiment II that a series of 21 electroconvulsive shocks dramatically attenuated an aversion to the taste of sweetened condensed milk. A similar effect was demonstrated by Ss in Group ECS-7, who were tested 7 days following the last treatment; these rats also completed 100 licks significantly faster than did sham-treated controls $(\mathrm{U}=10, \mathrm{p}<.01)$. Group ECS-14 was tested with sweetened condensed

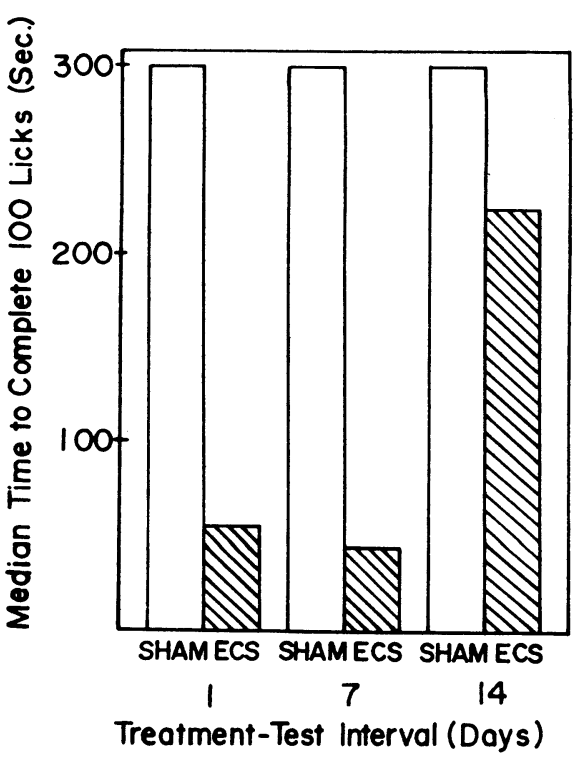

Fig. 3. Median time to complete 100 licks of sweetened condensed milk. Ss were injected with methyl atropine immediately following training with milk and were tested at various intervals after completion of 21 electroconvulsive shock treatments.

milk 14 days after the last electroconvulsive shock treatment, and scores for these Ss did not differ reliably from sham-treated controls $(\mathrm{U}=35.5, \mathrm{p}>.10)$. This result suggested that the aversion to the taste of sweetened condensed milk gradually reappeared after electroconvulsive shock treatments were terminated.

\section{DISCUSSION}

In Experiment I, a variety of doses of methyl atropine induced learned taste aversions to sweetened condensed milk. Repeated administrations of electroconvulsive shock reversed that taste aversion, as shown in Experiment II. This finding was replicated and extended in Experiment III. The finding that electroconvulsive shocks antagonized a learned taste aversion is consistent with earlier reports that these treatments reverse the effects of other punishments (Hunt \& Brady, 1951; Willi, 1969). Antagonism of the taste aversion gradually disappeared between 14 and 21 days after treatments were terminated. Brady (1951) reported reappearance of a conditioned emotional response 30 days after termination of electronconvulsive shock treatments.

Electroconvulsive shock has been reported to produce amnesia (Jarvik, 1972; McGaugh \& Dawson, 1971). It could be argued that the present results were due to retrograde amnesia following electroconvulsive shock. This is an unsatisfactory explanation, because retrograde amnesia ordinarily does not occur when intervals longer than $6 \mathrm{~h}$ elapse between training and electroconvulsive shock administration (McGaugh \& Dawson, 1971). In the present experiments, the interval was 4 days and is considerably longer than the postulated retrograde amnesia gradient. Repeated administrations of 
electroconvulsive shock have been shown to attenuate response suppression without impairing other well-established baseline behaviors (Hunt \& Brady, 1951; Willi, 1969). In addition, Gellhorn, Kessler, and Minatoya (1942) reported that electroconvulsive shock reinstated a previously extinguished conditioned avoidance response but did not impair the avoidance response itself. In view of these considerations, it appears that electroconvulsive shock can release responding that has been suppressed by a taste aversion, a conditioned emotional response, or extinction. These results are more consistent with a "disinhibitory" rather than a retrograde amnesia interpretation.

Vanderwolf (1963) suggested that apparent disinhibitory effects observed after repeated administrations of electroconvulsive shock may reflect selective alteration of inhibitory mechanisms. The results obtained in the present experiments are consistent with this notion and emphasize that the "disinhibitory" effect of repeated administrations of electroconvulsive shock is not permanent.

The present experiments were designed to study the effects of repeated administrations of electroconvulsive shock on a learned taste aversion. In these experiments, learned aversions that followed the association of ingestion of sweetened condensed milk with methyl atropine were temporarily reversed by repeated administrations of electroconvulsive shock. This finding is similar to that of other experiments in which the effects of punishment were reversed by repeated electroconvulsive shock administrations and emphasize that learned taste aversions appear to resemble other effects of punishment.

\section{REFERENCES}

Berger, B. D. Conditioning of food aversions by injections of psychoactive drugs. Journal of Comparative \& Physiological Psychology, 1972, 81, 21-26.

Brady, J. V. The effect of electro-convulsive shock on a conditioned emotional response: The permanence of the effect. Journal of Comparative \& Physiological Psychology, $1951,44,507-511$.

Cappell, H., \& LeBlanc, A. E. Punishment of saccharin drinking by amphetamine in rats and its reversal by chlordiazepoxide. Journal of Comparative \& Physiological Psychology, 1973, 85, 97-104.

Carlton, P. L., \& Vogel, J. R. Habituation and conditioning. Journal of Comparative \& Physiological Psychology, 1967, 63, 348-351.

Clody, D. E., Vogel, J. R., \& Taub, P. Chlordiazepoxide antagonism of the acquisition and performance of a conditioned food aversion in rats. Physiology \& Behavior, in press.

Geller, I., \& Seifter, J. The effects of meprobamate, barbiturates, d-amphetamine and promazine on experimentally induced conflict in the rat. Psychopharmacologia, 1960, 1, 482-492.

Gellhorn, E., Kessler, M., \& Minatoya, H. Influence of metrazol, insulin hypoglycemia and electrically induced convulsions on reestablishment of inhibited conditioned reflexes. Proceedings of the Society for Experimental Biology \& Medicine, 1942, 50, 260-262.

Hunt, H. F., \& Brady, J. V. Some effects of electroconvulsive shock on a conditioned emotional response ("Anxiety"). Journal of Comparative \& Physiological Psychology, 1951, 44, 88-98.

Jarvik, M. E. Effects of chemical and physical treatments on learning and memory. Annual R eview of Psychology, 1972 $23,457-485$.

Lubow, R. E. Latent inhibition. Psychological Bulletin, 1973, 79, 398-407

McGaugh, J. L., \& Dawson, R. G. Modification of memory storage processes. Behavioral Science, 1971, 16, 45-63.

Revusky, S. \& Garcia, J. Learned associations over long delays. In G. H. Bower and J. T. Spence (Eds.), The psychology of learning and motivation-Advances in research \& Theory IV. New York: Academic Press, 1970.

Vanderwolf, C. H. Improved shuttle-box performance following electroconvulsive shock. Journal of Comparative \& Physiological Psychology, 1963, 56, 983-986.

Vogel, J. R., \& Clody, D. E. Habituation and conditioned food aversion. Psychonomic Science, 1972, 28, 275-276.

Willi, F. J. P. The effect of electroconvulsive shock on a conditioned emotional response in the rhesus monkey. British Journal of Psychology, 1969, 60, 509-521.
(R eceived for publication June 27, 1974; revision received July $25,1974$. 